\title{
Teaching with the Microscopy Society of America's Sandbox
}

\author{
C. Zona ${ }^{1}$, H. Ullberg ${ }^{2}$, B. Dean ${ }^{2}$, C. Gorman ${ }^{1}$ and W. Zawadowski ${ }^{1}$ \\ 1. Hooke College of Applied Sciences, Westmont, IL USA \\ 2. McCrone Associates, Westmont, IL USA
}

Beginning in 1998 with a request for a "handful of sand" on the Microscopy Society of America's (MSA) List Server, the MSA Sandbox has grown to an inventory of more than 500 sands from all around the world, with donations continuing to be added each month. The Sandbox is an outgrowth of Activity 6 from Microscopic Explorations, a GEMS/MSA teachers' manual that helps middle school teachers introduce the "microworld" with written materials and instructions for 10 classroom lessons (1). The Project MICRO Sandbox program lets science teachers request up to six sand samples for use in their classrooms. Although the Sandbox was originally intended to assist middle school science teachers in developing a curriculum that incorporates the use of the microscope, the decision was made early on not to exclude requests based on academic grade level, but rather to encourage participation from teachers at all levels of learning. This has resulted in a mix of participants from elementary schools introducing the concept of magnification, to college professors interested in the professional development of science teachers. The program has also honored requests from a wide variety of educational programs and institutions, including, home-school teachers, local libraries, Girl Scout troops, charter school science teachers, science summer programs, after school science clubs, $4 \mathrm{H}$ environmental education programs, and children's museums.

The Sandbox provides a useful resource for science teachers who are tasked with providing cross-cutting curriculum materials that align with the Next Generation Science Standards (2-3). The sand samples have been used within science curricula in a number of creative ways, providing an avenue for science teachers to develop interesting and intriguing programs. Science teachers working with foreign language teachers have requested sands from countries where a particular language is spoken. Others have employed the sand samples to talk about erosion and weathering, texture, color, and grain sizes. A number of forensic science units have used the sands from the collection as part of a crime scene investigation. The sand samples have provided additional content in other curriculum programs such as Kindergarten Rocks (4). The Sandbox requests come full circle with a handful of MSA members who have requested sands for local outreach programs in their communities.

In true Microscopic Explorer fashion, we will further examine the many uses of the requested sand samples, along with the types of educators requesting the sand, how it is being used in the classroom and beyond. Topics regarding current updates and future plans for the Sandbox will also be discussed, including the challenges of providing photographs and bulk elemental data acquisition of each sand sample, and how Sandbox activities can be used to align with the Next Generation Science Standards.

\section{References:}

1. Microscopic Explorations: A GEMS Festival Teacher's Guide, Great Explorations in Math and Science, Lawrence Hall of Science, University of California at Berkeley, 19982007.

2. A Framework for K-12 Science Education: Practices, Crosscutting Concepts, and Core Ideas. National Academies Press, Washington D.C. 2012.

3. Next Generation Science Standards, www.nextgenscience.org/next-generation-sciencestandards, 2013.

4. Kindergarten Rocks, Math/Science Nucleus, Freemont, CA, 2013 www.msnucleus.org. 

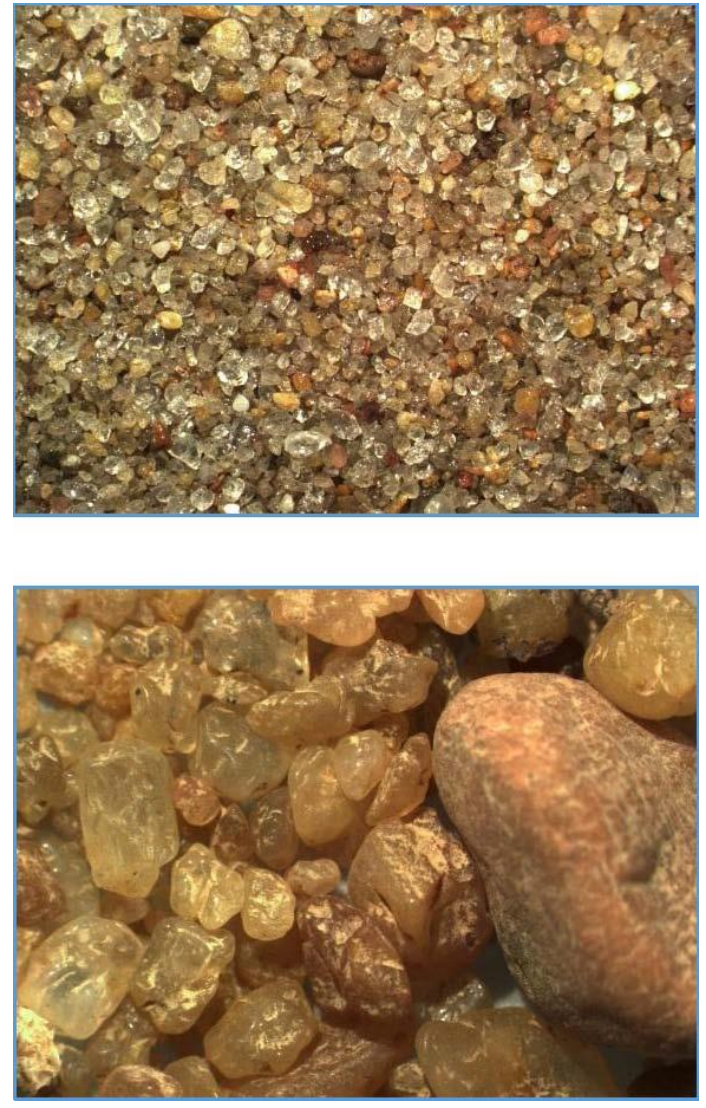

MSA Sandbox Sample Giza, Egypt 15X

MSA Sandbox Sample Eclipse Path, Mozambique $15 \mathrm{X}$

Sandbox activity at Summer microscopy workshop for science teachers (2013)

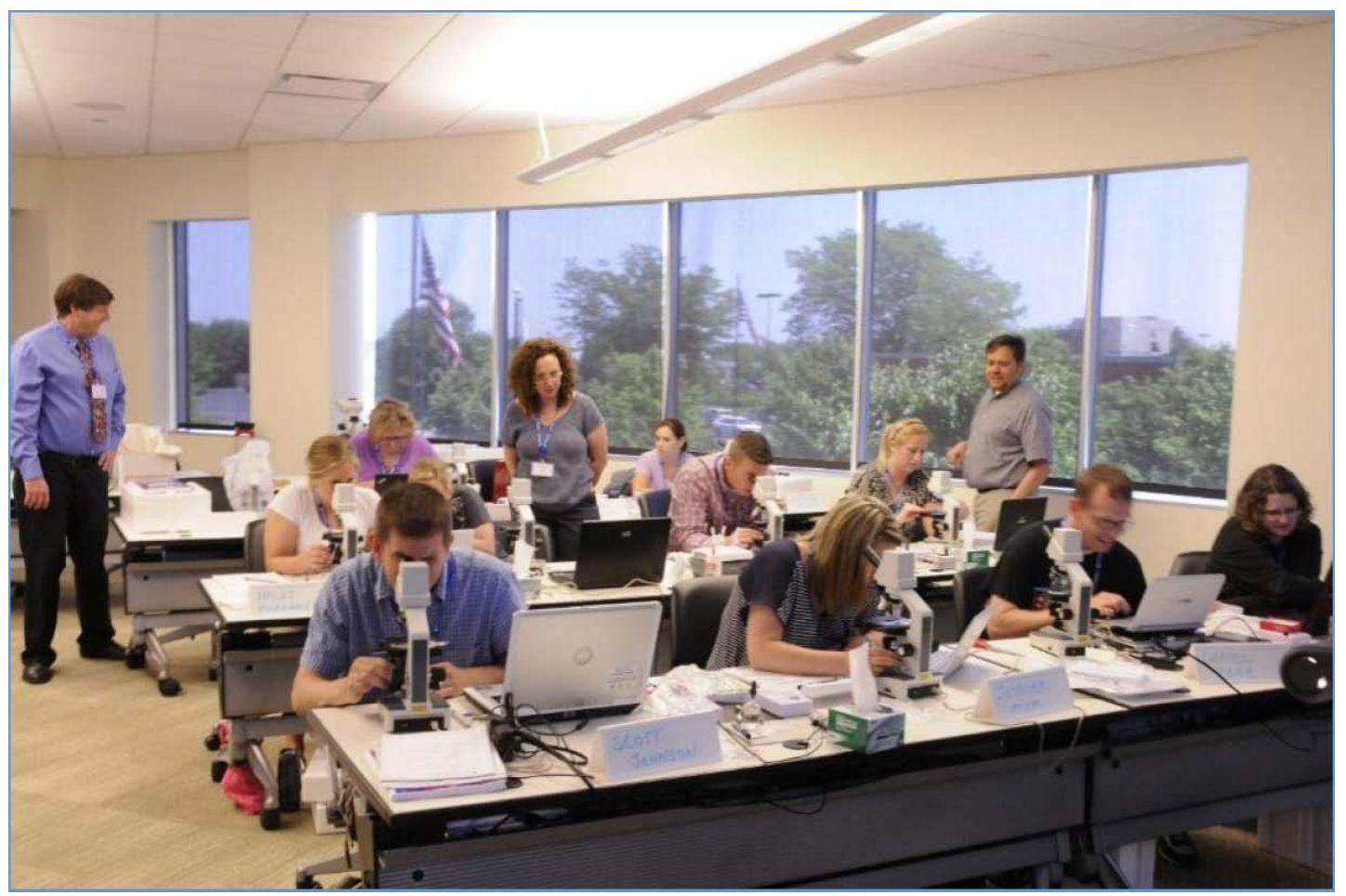

